\title{
PARTIÇÃO PLUVIOMÉTRICA EM FITOFISIONOMIAS DO CERRADO
}

\author{
partition rainfall in the savanna vegetation types
}

\author{
Fábio Carvalho * \\ Hildeu Ferreira da Assunção ** \\ Iraci Scopel $* * *$
}

\begin{abstract}
Resumo
O presente trabalho teve como objetivo determinar as partições pluviométricas - interceptação (I); precipitação interna (PI); precipitação efetiva (PE) e abstração inicial (AI) - em uma mata de encosta de cerrado da Bacia Hidrográfica do Córrego do Queixada, no município de Jataí (GO), em três fitofisionomias (cerrado stricto sensu; cerradão e mata ciliar) no período de outubro de 2009 a março de 2011. Foram instalados equipamentos para obtenção da precipitação total (P), da PI e da PE, determinando-se, então, a I e a AI. Verificou-se que a PI foi de $76 \%$, a I, foi de $25,6 \%$, a PE, $24,3 \%$ e a AI foi de $51,6 \%$. Na primavera e no inverno, períodos de muito baixos índices pluviométricos, houve diferença na variância para a PI a 5\% de probabilidade. Os períodos do outono e do verão apresentaram os maiores índices pluviométricos e não houve diferença na análise da variância a 5\% de probabilidade. Portanto, pode-se concluir que as três fitofisionomias tem comportamento semelhante em relação às partições pluviométricas.

Palavras-chave: Interceptação, Abstração inicial, Cerrado.

Abstract

This article aims to determine the rainfall partitions - interception (I); throughfall (PI); effective rainfall (PE) and initial abstraction (AI) - in hillside forest of savannah in the 'Queixada' watershed, at Jatai country, Goiás state, and In three vegetation types (cerrado stricto sensu; cerradão and riparian vegetation) on the period from October 2009 to March 2011. Equipment was installed to obtain rainfall (P) data, PI, and PE data, in order to determine the I and the AI. It was found that the percentage of PI was 76, of PE, was 24.3, of I, 25.6, and of AI, 51.5\%, in the period. The periods of lower rainfall as winter and spring, had different variances, at $5 \%$ probability for PI. The periods of summer and of fall had the highest rainfall and no differences in the results of variance analysis, at 5\% probability. Then, the three kind of phytophysiognomies had no differences in the rainfall partitions.
\end{abstract}

Key words: Interception, Initial abstraction, Savannah.

\begin{abstract}
Resumen
Este estúdio tuvo como objetivo determinar las particiones de la precipitación (P) como: interceptación (I); precipitación interna $(\mathrm{PI})$; precipitación efectiva $(\mathrm{PE})$ y abstracción inicial, en un bosque de una ladera de sabana, cuenca del Arroyo Queixada, en el município de Jataí (GO), en tres tipos de vegetación (cerrado en sentido estricto-savana-, cerrado y bosque de galeria) en el período de octubre/2009 a marzo de 2011. Se instaló un equipo para obtener la precipitación total (P), la PI y la PE, com la finalidad de obtener, entonces, la I y la AI. Se encontró que la PI fue 76\% de la P, el I fue $25,6 \%$, el PE fue $24,3 \%$ y la AI fue $51,6 \%$ de la P. En la primavera y en lo invierno, períodos de lluvias muy bajas, hubo diferencia en la varianza de PI, en el $5 \%$ de probabilidad. Los períodos de verano y de otoño tuvieron la major precipitación y no hubo diferencias en el análisis de la varianza, en el 5\% de probabilidad. Por lo tanto, se puede concluir que los tres tipos de vegetación tienen un comportamiento similar en relación a las particiones de las lluvias.
\end{abstract}

Palabras clave: Interceptación, Abstracción inicial, Sabana.

(*) Mestre em Geografia pela Universidade Federal de Goiás (Campus Jataí); Rua Riachuelo, n¹510; CP - 03, CEP - 75804020; Jataí (GO), Brasil - Tel.: (+ 55 64) 3606-8110 - fabioufg2222@yahoo.com.br

(**) Prof. Dr. da Pós-Graduação em Geografia da Universidade Federal de Goiás (Campus Jataí); BR-364, km 192 - Zona Rural; CP - 03, CEP - 75804-020; Jataí (GO), Brasil - Tel.: (+ 55 64) 3606-8334 - hildeu@yahoo.com.br

(***) Prof. Dr. da Pós-Graduação em Geografia da Universidade Federal de Goiás (Campus Jataí); BR-364, km 192 - Zona Rural; CP - 03, CEP - 75804-020; Jataí (GO), Brasil - Tel.: (+ 55 64) 3606-8134; e-mail: iraciscopel@gmail.com 


\section{INTRODUÇÃO}

O processo de interceptação da chuva pela vegetação (I) interfere significativamente no balanço hídrico das bacias hidrográficas. As florestas, nas bacias hidrográficas, possuem a capacidade de reduzir-“regularizar" a vazão superficial dos corpos d'água de uma bacia hidrográfica. A vegetação nas bacias hidrográficas possibilita que processos como a infiltração e a evapotranspiração funcionem naturalmente, onde a infiltração alimenta as águas subterrâneas e a evapotranspiração novas chuvas, regulando o ciclo hidrológico (GÊNOVA et al., 2007; LIMA, 2000; OLIVEIRA et al., 2008).

A I é o processo pelo qual a água da precipitação total (P) é retida pelas folhas, pelos ramos, por galhos e pelos troncos, evaporando diretamente para a atmosfera. Da quantidade de água precipitada, parte dela irá atravessar o dossel, constituindo a precipitação interna (PI) e, outra parte, escoa pelos troncos, constituindo o escoamento pelo tronco (Et) (LIMA, 2000).

A água da PI e do Et poder-se-á transformar-se em precipitação efetiva (PE), que por sua vez é definida como a quantidade de água que alimenta as águas subterrâneas e, também, supre as necessidades de água das plantas, alimentando o processo de evapotranspiração dos vegetais. (LIMA, 2000; ARCOVA et al., 2003)

Além da I, existe a abstração inicial (AI), caracterizada como a parcela da P que ocorreu antes do início PE. Os valores da I, da PI, do Et, da PE e da AI variam em conformidade com fatores, como, espécie arbórea, arbustiva ou herbáceas, as quais possuem estruturas distintas e, também, quanto ao volume de biomassa existente na bacia hidrográfica o qual interfere nos índices de I, reduzindo a quantidade de água que chega ao solo. Os aspectos morfológicos das plantas também são outros fatores que interferem nos índices de I (LIMA, 2000; MELLO et al., 2003).

Nos estudos do ciclo hidrológico muita das vezes o processo de I é negligenciado ou estudado separadamente (LIMA; NICOLIELO, 1983). Estudos de interceptação da chuva pela vegetação são escassos para o cerrado goiano necessitando de investimentos para o conhecimento deste fenômeno que é fundamental para resultados confiáveis do funcionamento hidrológico de uma bacia hidrográfica.

Objetiva-se, neste trabalho, caracterizar as partições pluviométricas (I, PI, PE e AI) na Mata do Córrego do Queixada e em três fitofisionomias de Cerrado, localizadas na bacia hidrográfica do Córrego do Queixada (BHQXD), no município de Jataí, em Goiás.

\section{MATERIAL E MÉTODOS}

\section{Localização e descrição geral da área de estudo}

Este estudo foi conduzido em uma mata de encosta da BHQXD, município de Jataí (GO), estando mapeada na carta identificada pela quadrícula UTM-22, sendo compreendida pelas coordenadas E 419.124,99 m, N 8.028.060,83 m, E 423.105,19 m, N 8.021.056,99 m, com uma altitude média de $744 \mathrm{~m}$. Esta mata se caracteriza por apresentar três fitofisionomias do bioma Cerrado: mata ciliar, cerradão e cerrado stricto sensu.

A BHQXD, geologicamente, pertence à formação Serra Geral (Jksg), Grupo São Bento, caracterizada por derrames basálticos (RADAMBRASIL, 1983).

O clima o qual se insere o estudo está classificado por Köppen em Tropical de Savana (Aw), com a ocorrência de chuvas no verão e seca no inverno.

De acordo com Assunção et al. (1999), o município de Jataí apresenta uma distribuição pluviométrica bastante variável de um ano para outro, por exemplo, no período de 1980 a 1999, verificou-se que as alturas pluviométricas anuais oscilaram entre $702 \mathrm{~mm}$, em 1998 e 2.138,2 mm, em 1983.

A temperatura média anual sofre variações que vai de "[...] 18,2 ${ }^{\circ} \mathrm{C}$ para o mês mais frio (julho) a $24,4{ }^{\circ} \mathrm{C}$ para o mês mais quente (outubro)". As análises do balanço hídrico mostraram que os "índices de deficiência hídrica" foram observados nos meses que se estendem de maio a setembro e os excedentes hídricos de novembro a abril (Idem, p.4). 
O solo predominante na BHQXD é o Latossolo Vermelho Distroférrico, com horizonte A moderado e textura muito argilosa (RADAMBRASIL, 1983), consequentemente, refletindo na atuação dos fatores de formação do solo e dos processos pedológicos de intemperização.

O Cerrado é definido como uma região de ecótono, onde encontramos formações florestais e savânicas - "[...] floresta-ecótono-campo" (CONTI; FURLAN, 2003, p.177). A formação de campo seria caracterizada pelo campo limpo e pelo campo sujo, com predomínio de espécies herbáceas e arbustivas. Já a formação florestal seria constituída pelo Cerrado stricto sensu, e pelo Cerradão, encontrando-se espécies arbóreas e arbustivas. Entre estas formações - florestal e savânicas - estaria uma região de ecótono.

\section{Procedimentos}

Para o monitoramento das partições pluviométricas na Mata do Queixada, foram confeccionados instrumentos específicos para a coleta dos dados da P, da PI e da PE.

Os dados de $\mathrm{P}$ foram obtidos com a instalação de um pluviômetro acima da copa das árvores. Estes pluviômetros - de formato cilíndrico - com área de captação de $162 \mathrm{~cm}^{2}$ foram instalados com a ajuda de barras de cano de ferro galvanizado, que fixados no tronco das árvores, mantinha o pluviômetro acima das copas das árvores.

O pluviômetro já fixado acima das copas conectava-se a uma mangueira que transportava a água captada a um reservatório na superfície, onde era armazenada a água captada das chuvas para as leituras. Na Figura 1 visualizam-se alguns passos para a instalação do pluviômetro totalizador. Em cada fitofisionomia considerada - cerrado, cerradão e mata ciliar - foi instalado um único instrumento.

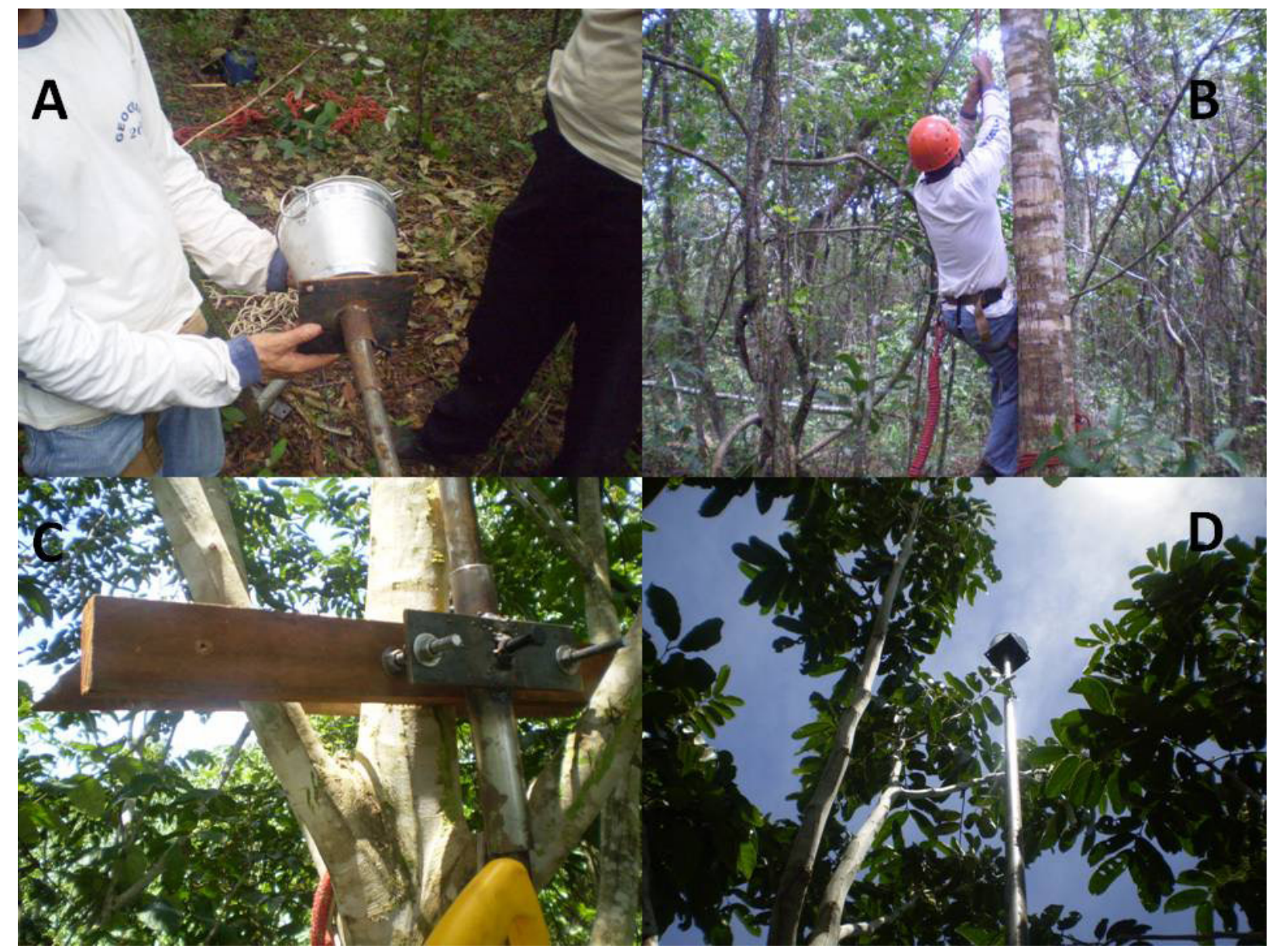

Figura 1 - A - pluviômetro fixado na extremidade do cano galvanizado; B - instante dos trabalhos de fixação das estruturas no tronco da árvore; $\mathrm{C}$ - armação que mantêm o cano galvanizado fixado ao tronco; D - pluviômetro totalizador acima das copas das árvores 
Pluviômetros foram instalados na superfície da mata para obtenção dos dados da PI, com uma área de captação de $452 \mathrm{~cm}^{2}$, onde a chuva era captada e armazenada em um reservatório para as leituras (Figura 2 - B). Em cada uma das três fitofisionomias foram instalados quatro (4) pluviômetros similares para a coleta dos dados de PI.

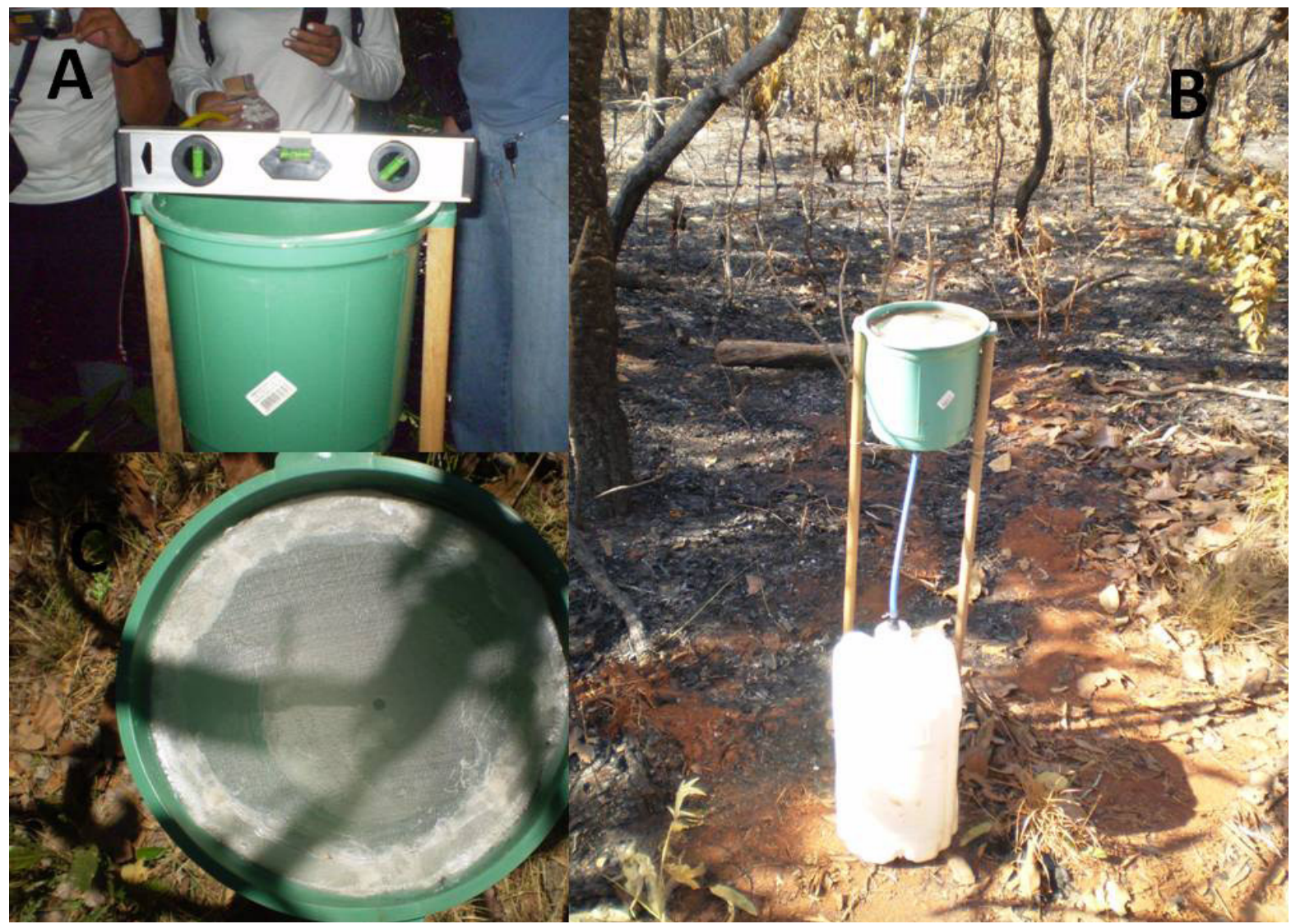

Figura 2 - A - Instantes da instalação do equipamento para a coleta da precipitação interna (PI); B - Perfil do equipamento com o reservatório; C - Visão da área de captação e tela de proteção

Admitindo que o Et é a menor parcela dentre as variáveis para se determinar a I, podendo ser inferior a 5\% (LIMA, 2000), em termos práticos não foi considerada a atuação desta componente. Portanto, considerou-se a seguinte expressão para a determinação da I:

$\mathrm{I}=\mathrm{P}-\mathrm{PI}$, onde:

$\mathrm{I}=$ interceptação;

$\mathrm{P}=$ precipitação total;

PI = precipitação interna;

Os dados de AI foram determinados neste trabalho como sendo:

$\mathrm{AI}=(\mathrm{P}-\mathrm{PE}) / \mathrm{P}$

$\mathrm{AI}=$ abstração inicial;

$\mathrm{P}=$ precipitação total;

$\mathrm{PE}=$ precipitação efetiva; 
Para a determinação da AI das áreas de cerrado desta pesquisa levou-se em conta os dados de $P E$ que foram obtidas a $15 \mathrm{~cm}$ abaixo da superfície do solo e que serão apresentados a seguir.

Os dados de PE foram obtidos através da instalação de um recipiente a $15 \mathrm{~cm}$ abaixo da superfície do solo - superfície da floresta. Estes $15 \mathrm{~cm}$ foram retirados com a ajuda de um "cilindro cortante", que possui $50 \mathrm{~cm}$ de diâmetro por $15 \mathrm{~cm}$ de altura, onde o mesmo foi cravado no solo, retirando a porção de solo intacta (Figura 3 - A). Posteriormente foi escavada mais uma profundidade de $40 \mathrm{~cm}$, onde o recipiente com área de $452 \mathrm{~cm}^{2}$ e com capacidade de armazenamento de água de aproximadamente nove litros d'água foi inserido, e por cima encaixa-se uma "tampa-peneira" especial. Uma pequena quantidade de brita foi colocada por cima da tampa-peneira para a retenção de sedimentos percolados juntamente com a água (Figura 3 - B e C).

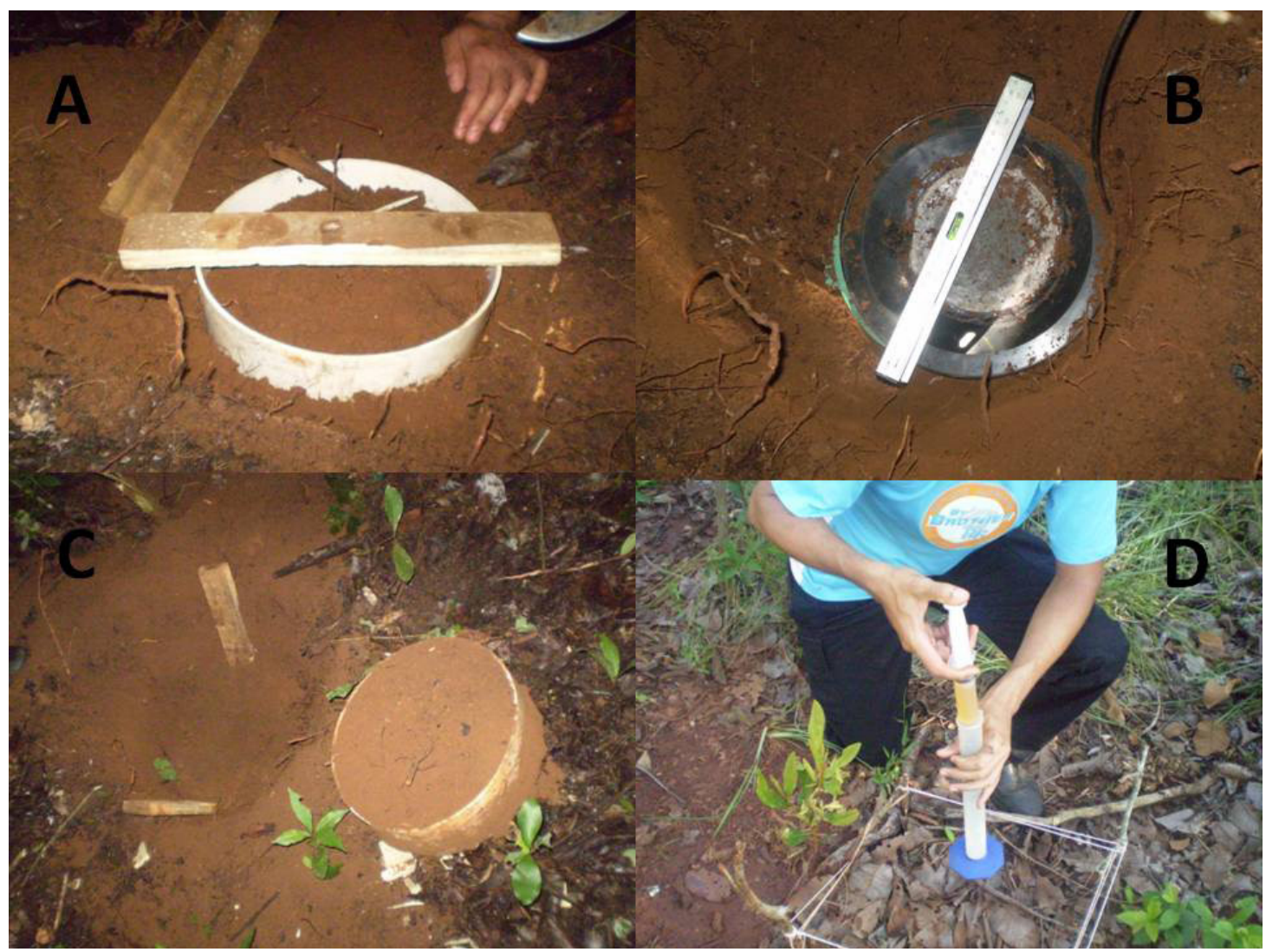

Figura 3 - A - cilindro cortante no momento em que será inserido no solo para a retirada da camada superficial de solo; B - recipiente inserido no solo; C - local onde será inserido o recipiente para a coleta dos dados da precipitação efetiva; D - coleta dos dados da precipitação efetiva

Uma mangueira instalada no fundo do recipiente com uma saída para a superfície possibilitou a retirada da água infiltrada, com o auxílio de uma seringa comum. A água retirada foi mensurada em uma proveta graduada em mililitros (Figura 4 - D). O banco de dados da PE foi composto por quatro repetições em cada uma das três fitofisionomias analisadas.

Todos os dados de P, de PI e da PE foram registrados e manipulados através do software Excel, convertendo-os para milímetros de chuva por meio da seguinte equação:

$\mathrm{H}(\mathrm{mm})=(\mathrm{V}(\mathrm{mL})) /\left(\mathrm{A}\left(\mathrm{cm}^{\wedge} 2\right)\right) \times 10$, onde:

$\mathrm{H}=$ altura da chuva em milímetros;

$\mathrm{V}=$ volume captado em mililitros;

$\mathrm{A}=$ área de captação do pluviômetro em $\mathrm{cm}^{2}$; 
Os registros dos dados tiveram início em outubro de 2009 e se estenderam até março de 2011, e as coletas dos dados eram realizadas semanalmente. A localização geográfica de cada instrumento mencionado anteriormente pode ser conferida na Tabela 1.

Tabela 1 - Coordenadas UTM-22 dos pontos para a coleta de P, PI e PE

\begin{tabular}{|c|c|c|c|c|c|}
\hline FITOFISIONOMIA & INSTR. & REP. & LONG. (m) & LAT. $(\mathrm{m})$ & ALT. (m) \\
\hline \multirow{5}{*}{ MATA } & $\mathrm{P}$ & 1 & $421.462 \mathrm{E}$ & $8.024 .564 \mathrm{~N}$ & 733 \\
\hline & \multirow{4}{*}{ PI } & 1 & $421.479 \mathrm{E}$ & $8.024 .546 \mathrm{~N}$ & 749 \\
\hline & & 2 & $421.484 \mathrm{E}$ & $8.024 .536 \mathrm{~N}$ & 748 \\
\hline & & 3 & $421.487 \mathrm{E}$ & $8.024 .557 \mathrm{~N}$ & 748 \\
\hline & & 4 & $421.466 \mathrm{E}$ & $8.024 .563 \mathrm{~N}$ & 745 \\
\hline \multirow{4}{*}{ CILIAR } & \multirow{4}{*}{ PE } & 1 & $421.480 \mathrm{E}$ & $8.024 .547 \mathrm{~N}$ & 749 \\
\hline & & 2 & $421.484 \mathrm{E}$ & $8.024 .536 \mathrm{~N}$ & 747 \\
\hline & & 3 & $421.485 \mathrm{E}$ & $8.024 .555 \mathrm{~N}$ & 747 \\
\hline & & 4 & $421.467 \mathrm{E}$ & $8.024 .562 \mathrm{~N}$ & 748 \\
\hline \multirow{9}{*}{ CERRADÃO } & $P$ & 1 & $421.224 \mathrm{E}$ & $8.024 .714 \mathrm{~N}$ & 759 \\
\hline & \multirow{4}{*}{$\mathrm{PI}$} & 1 & $421.221 \mathrm{E}$ & $8.024 .712 \mathrm{~N}$ & 717 \\
\hline & & 2 & $421.205 \mathrm{E}$ & $8.024 .719 \mathrm{~N}$ & 754 \\
\hline & & 3 & $421.213 \mathrm{E}$ & $8.024 .708 \mathrm{~N}$ & 771 \\
\hline & & 4 & $421.231 \mathrm{E}$ & $8.024 .730 \mathrm{~N}$ & 758 \\
\hline & \multirow{4}{*}{$\mathrm{PE}$} & 1 & $421.220 \mathrm{E}$ & $8.024 .730 \mathrm{~N}$ & 752 \\
\hline & & 2 & $421.191 \mathrm{E}$ & $8.024 .717 \mathrm{~N}$ & 762 \\
\hline & & 3 & $421.207 \mathrm{E}$ & $8.024 .715 \mathrm{~N}$ & 771 \\
\hline & & 4 & $421.241 \mathrm{E}$ & $8.024 .727 \mathrm{~N}$ & 757 \\
\hline \multirow{9}{*}{ CERRADO } & $P$ & 1 & $420.525 \mathrm{E}$ & $8.024 .915 \mathrm{~N}$ & 780 \\
\hline & \multirow{4}{*}{$\mathrm{PI}$} & 1 & $420.527 \mathrm{E}$ & $8.024 .897 \mathrm{~N}$ & 779 \\
\hline & & 2 & $420.537 \mathrm{E}$ & $8.024 .909 \mathrm{~N}$ & 780 \\
\hline & & 3 & $420.528 \mathrm{E}$ & $8.024 .924 \mathrm{~N}$ & 807 \\
\hline & & 4 & $420.457 \mathrm{E}$ & $8.024 .993 \mathrm{~N}$ & 791 \\
\hline & \multirow{4}{*}{ PE } & 1 & $420.535 \mathrm{E}$ & $8.024 .906 \mathrm{~N}$ & 779 \\
\hline & & 2 & $420.539 \mathrm{E}$ & $8.024 .905 \mathrm{~N}$ & 779 \\
\hline & & 3 & $420.530 \mathrm{E}$ & $8.024 .922 \mathrm{~N}$ & 786 \\
\hline & & 4 & $420.511 \mathrm{E}$ & $8.025 .004 \mathrm{~N}$ & 796 \\
\hline
\end{tabular}

INSTR. - Instrumentos; REP. - Repetições; P - precipitação total; PI - precipitação interna; PE - precipitação efetiva

As análises das partições pluviométricas foram feitas periodicamente conforme Tabela 2.

Os dados do período do verão foram compostos pelos dados dos meses de novembro, de dezembro e de janeiro. Para o período do outono os dados foram compostos pelos meses de fevereiro, de março e de abril. O inverno ficou definido com os dados dos meses de maio, de junho e de julho. A primavera foi composta pelos dados dos meses de agosto, de setembro e de outubro.

Todos os dados das partições pluviométricas foram submetidos à análise de variância ao nível de $5 \%$ de probabilidade e as diferenças ou semelhanças entre as variâncias foram discutidas e/ou justificadas.

\section{RESULTADOS E DISCUSSÃO}

Na Tabela 3 verificam-se os valores absolutos e percentuais das partições pluviométricas - PI; PE; I e AI em três fitofisionomias de cerrado de uma mata de encosta da BHQXD para o período do verão de 2009/2010. 
Tabela 2 - Meses que foram levados em conta para as análises sazonais das partições pluviométricas na bacia hidrográfica do córrego do Queixada

\begin{tabular}{c|c}
\hline \multicolumn{2}{c}{ PERÍODO } \\
\hline INVERNO & MAIO, JUNHO, JULHO \\
\hline PRIMAVERA & AGOSTO, SETEMBRO, OUTUBRO \\
\hline VERÃO & NOVEMBRO, DEZEMBRO, JANEIRO \\
\hline OUTONO & FEVEREIRO, MARÇO, ABRIL \\
\hline
\end{tabular}

Tabela 3 - Partição pluviométrica na Mata do Queixada para o período do verão

\begin{tabular}{ccccccccccccc}
\hline FITOFISIONOMIA & P $(\mathbf{m m})$ & PI (mm) & PI (\%) & PE (mm) & PE (\%) & I (mm) & I (\%) & Al (mm) & Al (\%) \\
\hline CERRADÃO & 464,5 & 335,3 & 72,2 & 114,5 & 24,7 & 120,3 & 25,9 & 220,8 & 47,5 \\
\hline CERRADO & 464,5 & 332,7 & 71,6 & 111,4 & 24,0 & 129,3 & 27,8 & 221,3 & 47,6 \\
\hline MATA CILIAR & 464,5 & 333,2 & 71,7 & 94,7 & 20,4 & 94,7 & 20,4 & 238,4 & 51,3 \\
\hline
\end{tabular}

P - precipitação; PI - precipitação interna; PE - precipitação efetiva; I - interceptação; AI - abstração inicial;

Todas as partições pluviométricas das fitofisionomias durante o verão, submetidas à análise de variância ao nível de 5\% de probabilidade, não diferiram entre si. Segundo Lima (2000), uma chuva com um volume de $5 \mathrm{~mm}$, quase que $100 \%$ desta será interceptada pela vegetação (retida nas copas das árvores e evaporada para a atmosfera), e que em um evento pluviométrico de $100 \mathrm{~mm}$, apenas $5 \%$ desta será retida pela vegetação, sendo o restante escoado pelo tronco ou mesmo precipitando internamente na serrapilheira. Neste sentido as variâncias similares das fitofisionomias no período do verão poderão ser devido à intensidade e o volume de chuva registrados neste período, sendo o segundo período em volume de $\mathrm{P}$ para os períodos analisados, e onde as plantas encontram-se com suas necessidades hídricas estabelecidas em relação aos outros períodos.

O percentual em relação à precipitação total média para as três fitofisionomias para o período do verão, a PI foi de $71,8 \%$, a I foi de $27,6 \%$, a PE foi de $23 \%$ e a AI foi de $48,8 \%$. Onozawa et al. (2009) trazem dados de I em florestas de bambu no Japão, que é da ordem de 10,8 \%, sendo que para o período de um ano foi inferior a $20 \%$, exceto no mês de outubro, mês de menor P. A PI na floresta de bambu do Japão foi de 73,9\%, valores próximos aos encontrados no período do verão para as fitofisionomias do cerrado.

Os valores de I, de PI variam em conformidade com diversos fatores, tais como, espécie vegetal, grau de desenvolvimento da espécie e outros fatores que interferem diretamente, como, a insolação, o volume e a intensidade da P. Os valores reduzidos da I no cerrado em relação a florestas de bambu explicam-se pela fitofisionomia da vegetação e o período comparado, que foi o do verão. Conforme Oliveira et al. (2008), os valores de I em florestas da Amazônia Oriental foram de 21,5\%, valores próximos aos encontrados na Mata do Queixada.

Na Tabela 4 verificam-se os percentuais e os valores absolutos das partições pluviométricas PI, PE, I e AI para as três fitofisionomias de cerrado da mata de encosta da BHQXD no período do outono de 2010. 
CARVALHO, F. ; ASSUNÇÃO, H. F.; SCOPEL, I.

Tabela 4 - Partição pluviométrica na Mata do Queixada para o período do outono

\begin{tabular}{ccccccccccccc}
\hline FITOFISIONOMIA & P (mm) & PI (mm) & PI (\%) & PE (mm) & PE (\%) & I (mm) & I (\%) & Al (mm) & Al (\%) \\
\hline CERRADÃO & 775,8 & 557,2 & 71,8 & 158,0 & 20,4 & 237,0 & 30,5 & 399,2 & 51,5 \\
\hline CERRADO & 775,8 & 551,1 & 71,0 & 168,0 & 21,7 & 227,6 & 29,3 & 383,1 & 49,4 \\
\hline MATA CILIAR & 775,8 & 586,4 & 75,6 & 199,2 & 25,7 & 165,1 & 21,3 & 387,2 & 49,9 \\
\hline
\end{tabular}

P - precipitação total; PI - precipitação interna; PE - precipitação efetiva; I - interceptação; AI - abstração inicial;

As partições pluviométricas PI, PE, I e AI no período do outono mostraram-se semelhantes na análise de variância ao nível de 5\% de probabilidade. Na Amazônia Oriental os valores de PI registrados foram de 76,8\%, bem próximos aos encontrados no período do verão de 2009/2010 para a Mata do Queixada.

No período do outono foram registrados os maiores índices pluviométricos para todo o período analisado. A média de PI para as três fitofisionomias durante o outono foi de 564,9 mm (72,8\%), de PE foi de $175,1 \mathrm{~mm}(22,6 \%)$, de I foi de 209,9 $\mathrm{mm}(27,1 \%)$ e da AI para as três fitofisionomias foi de $389,8 \mathrm{~mm}(50,2 \%)$. Oliveira et al. (2008), apresentam os seguintes valores percentuais para a PE de $78,5 \%$, a PI de $76,8 \%$ e a I de $21,5 \%$ do total precipitado.

Na Tabela 5 verificam-se os resultados da análise de variância da PI das fitofisionomias para o período de inverno, que registrou uma P média de 49,5 $\mathrm{mm}$. Pela análise de variância a 5\% probabilidade, as fitofisionomias apresentaram diferenças estatisticamente significativas.

Tabela 5 - Teste de média para a precipitação interna para as diferentes fitofisionomias no período inverno

\begin{tabular}{lccc}
\hline FITOFISIONOMIA & MÉDIA (mm) & PI (\%) & EQUIVALÊNCIA' \\
\hline CERRADO & 47,3 & 95,6 & A \\
CERRADÃO & 39,8 & 80,4 & A \\
MATA CILIAR & 32,5 & 65,7 & B \\
\hline
\end{tabular}

${ }^{1}$ Letras iguais denotam médias iguais a $5 \%$ de probabilidade PI - precipitação interna

Houve diferença significativa entre a PI da mata ciliar e do cerrado, e entre a mata ciliar e o cerradão. A maior PI na fitofisionomia do cerrado deve-se à menor densidade de área foliar e maior penetração das gotas das chuvas ao alcance dos pluviômetros que captam a PI. Esta fitofisionomia possui plantas de menor porte e volume de biomassa, ou seja, espécies relativamente menores quando comparadas às espécies das outras fitofisionomias. Além da fitofisionomia cerrado possuir uma grande quantidade de gramíneas e arbustos, os instrumentos captadores da PI ficaram a $1 \mathrm{~m}$ da superfície (Figura 3 - B) e, portanto, não sofrendo a interferência das gramíneas. Teoricamente, na fitofisionomia cerrado, as gotas de chuva possuem maior chance de não ficarem retidas pelas copas das árvores visto que possuem menor área foliar em seu dossel.

Em resumo, a média da PI para as três fitofisionomias da Mata do Queixada no período do inverno foi de $80,6 \%$, valores próximos àqueles encontrados por Ferreira et al. (2005) em floresta de terra firme na Amazônia Central.

No caso da Mata do Queixada a menor PI na fitofisionomia mata ciliar é devida à maior área foliar de seu dossel, onde as gotas das chuvas possuem a maior probabilidade de serem interceptadas, corroborando com os dados da Amazônia Central (FERREIRA et al., 2005). 
Os dados de I apresentaram para o período de inverno na mata ciliar um valor de $10,6 \mathrm{~mm}$ $(21,4 \%)$, no cerradão de $7,1 \mathrm{~mm}(14,3 \%)$ e no cerrado de $6,1 \mathrm{~mm}(12,3 \%)$. Para o período de um ano os valores de I para florestas estacionais decíduas são da ordem de 13\% do total precipitado. Em florestas de coníferas estes valores podem chegar a 22\% da P (DUNNE; LEOPOLD, 1972). Para o inverno o cerradão apresentou um valor de PE de 2,2 mm (4,4\%), o cerrado de 1,3 mm $(2,6 \%)$ e a mata ciliar de $1,1 \mathrm{~mm}$ (2,2\%). Através da análise de variância ao nível de $5 \%$ de probabilidade, a I e a PE mostraram-se semelhantes entre si. Ressalta-se que os baixos índices de PE justificam-se pelas altas taxas de AI.

Na Tabela 6 verificam-se os resultados da análise de variância da AI para as três fitofisionomias no período de inverno.

Tabela 6 - Teste de médias para a abstração inicial nas três fitofisionomias, no período inverno

\begin{tabular}{ccccc}
\hline FITOFISIONOMIA & MÉDIA (mm) & Al (\%) & \multicolumn{1}{c}{ EQUIVALÊNCIA $^{1}$} \\
\hline CERRADO & 46,0 & 92,9 & A \\
\hline CERRADÃO & 37,6 & 76,0 & AB \\
\hline MATA CILIAR & 31,4 & 63,4 & B \\
\hline
\end{tabular}

${ }^{1}$ Letras iguais denotam médias iguais a 5\% de probabilidade AI - abstração inicial

Os dados da Tabela 6 indicam que para o período do inverno a fitofisionomia cerrado foi a que teve a maior média de AI em valores absolutos e a mata ciliar a menor AI. Neste período as plantas estão em estresse hídrico e isto explica os altos valores de AI que vão de 63,4\% a 92,9\% da P.

Os valores da AI para o inverno, superior a $90 \%$ na fitofisionomia cerrado se devem a uma série de fatores naturais e antrópicos. Primeiramente devido à presença de vegetação herbácea e uma grande quantidade de arbustos que levam a inferir que os sistemas radiculares destas plantas interferem na PE, e em segundo lugar estas áreas da fitofisionomia cerrado serviram como pastagens, encontrando-se atualmente como testemunhas, as trilhas de gado, o que induz a ser um solo mais compactado em relação às outras fitofisionomias, propiciando um maior escoamento superficial e menor recarga d'água subterrânea.

Dunne e Leopold (1972) trazem que a I por gramíneas são da ordem $10 \%$ a $20 \%$, podendo variar em conformidade com a sazonalidade e o grau de desenvolvimento do vegetal. No caso específico da fitofisionomia cerrado chegamos ao período do inverno a um valor de $92,9 \%$ de AI, o que evidencia alto poder de retenção de água pelas plantas e nas camadas superiores da superfície da fitofisionomia cerrado, principalmente em estações seca quando temos baixos volumes e intensidades pluviométricas.

As diferenças estatísticas pela análise de variância a 5\% de significância da AI entre as fitofisionomias, cerrado e mata ciliar são explicadas pela compactação do solo devido a ser no passado uma área de pastagem e juntamente com declividade induzir ao escoamento superficial.

$\mathrm{O}$ método CN (curve number) desenvolvido pelo Departamento Americano de Agricultura (USDA) é um dos métodos mais usados nos estudos de bacias hidrográficas e considera a AI como sendo de $20 \%$ do total precipitado. Este método foi desenvolvido para as condições dos EUA, ocorrendo distorções até mesmo neste território, não sendo recomendados para a obtenção de dados com precisão em áreas tropicais. Os valores de AI no período do inverno para o cerrado da Mata do Queixada são superiores as usados pelo método do curve number.

De acordo com Mello et al. (2003, p.497), os valores da AI devem ser determinados levando-se em conta dados do comportamento da $\mathrm{P}$, e não somente o total do volume precipitado. "Assim, por exemplo, se a PE ocorrer logo no início do evento, sua AI será zero [...]”. Portanto, os índices 
de AI variam em consonância com diversos fatores de onde ocorre o evento pluviométrico, como a intensidade da $\mathrm{P}$, características físicas da bacia hidrográfica e sazonalidade.

Concluindo a discussão sobre as análises das partições pluviométricas sazonais, na primavera houve uma P de 140,5 mm, uma PI na mata ciliar de 132,9 mm (94,6\%), no cerrado de $122,1 \mathrm{~mm}$ (86,9\%) e no cerradão de $114,1 \mathrm{~mm}(81,2 \%)$. Aplicando a análise de variância ao nível de 5\% de probabilidade as precipitações internas das fitofisionomias para o período da primavera mostraram-se semelhantes.

Na Tabela 7 verificam-se os dados da I no período da primavera onde se verifica uma diferença estatisticamente significativa, ao nível de $5 \%$ de probabilidade, entre a mata ciliar e o cerrado e entre o cerradão e a mata ciliar. Por outro lado, os dados não evidenciam diferenças significativas entre a mata ciliar e o cerradão.

Tabela 7 - Teste de média para a interceptação para as fitofisionomias no período da primavera

\begin{tabular}{cccc}
\hline FITOFISIONOMIA & MÉDIA (mm) & I (\%) & EQUIVALÊNCIA $^{1}$ \\
MATA CILIAR & 27,2 & 19,4 & A \\
CERRADÃO & 20,5 & 14,6 & A \\
CERRADO & 13,9 & 9,9 & B \\
& & & \\
\hline
\end{tabular}

${ }^{1}$ Letras iguais denotam médias iguais a $5 \%$ de probabilidade I - interceptação

Observa-se que, devido à maior biomassa e à capacidade de retenção de água pelas copas da fitofisionomia mata ciliar, obtiveram-se maiores índices de I da chuva pela vegetação no período da primavera. As literaturas consultadas informam que uma maior I ocorre em consonância com o maior volume de biomassa. A I do período da primavera é indicativa desta evidência, quando a maior I foi encontrada fitofisionomia "mata ciliar", onde há árvores mais altas e grossas, com maior cobertura do dossel, enquanto a fitofisionomia cerrado há uma menor I na primavera, de 9,9\%, devido, provavelmente, ao seu menor volume de biomassa, logo, retendo uma menor quantidade de água na copa das árvores. Este fato não indica que a fitofisionomia cerrado terá uma maior PE devido à menor I, pois, nesta fitofisionomia, como mencionado anteriormente, foi uma área de pastagem com a presença de trilhas do gado e tendo uma propensão a um solo mais compactado, dificultando a infiltração da água, o que teoricamente favorece o escoamento superficial.

No período da primavera de 2010, observou-se uma média de PE na fitofisionomia mata ciliar de $47,9 \mathrm{~mm}(34,1 \%)$, no cerrado encontrou-se o valor de $36,3 \mathrm{~mm}(25,8 \%)$ e no cerradão um valor de $36,5 \mathrm{~mm}(25,9 \%)$. Na análise de variância não encontramos diferenças significativas ao nível de $5 \%$ de probabilidade. Observe-se que, como mencionado anteriormente, a menor PE deu-se na fitofisionomia cerrado seguido do cerradão. A maior PE deu-se na fitofisionomia mata ciliar justificando a importância desta faixa de floresta para os cursos d'água das bacias hidrográficas. Na primavera os índices de AI foram para o cerrado de 85,8 $\mathrm{mm}(61,1 \%)$, para a mata ciliar de 85,0 mm $(60,5 \%)$ e para o cerradão de $77,6 \mathrm{~mm}(55,2 \%)$. As análises de variância não apresentam variâncias estatisticamente significativas ao nível de 5\% de probabilidade. A menor AI atribuída ao cerradão foi explicada pela alta capacidade de infiltração desta fitofisionomia o que reduz os índices de AI para o período da primavera.

A soma da P para o período de chuva analisado foi de $1.430 \mathrm{~mm}$ para uma média da PI para as três fitofisionomias de 1.061,6 mm. A I foi de 363,1 mm, a PE foi de 323,7 mm e uma AI de 737,7 $\mathrm{mm}$. Transformando os valores em percentagens da PI, I, PE e AI, em relação ao total precipitado têm-se os seguintes valores, respectivamente: $76 \%, 25,6 \%, 24,3 \%$ e $51,6 \%$. 
Kittredge et alii (1941), apud Lima (2000), encontraram os valores de I de 17 a $28 \%$ em plantações de pinheiros, sendo valores próximos a média encontrada para as três fitofisionomias consideradas da Mata do Córrego do Queixada que foi da ordem de 25,6\%. Voigt (1960) apud Lima (2000) encontrou em plantações de pinheiro o valor de $19 \%$ e $25 \%$, podendo ter valores superiores aos encontrados. Low (1972) apud Lima (2000), afirma que as taxas de I em florestas da Malásia podem chegar a $50 \%$, podendo variar para mais ou para menos.

Geiger (1966) apud Lima (2000) encontraram os valores de PI e de I de respectivamente: $34 \%$ e 38\%. Durante o período de estudo na Mata do Córrego do Queixada os valores de PI foram 76\%.

$\mathrm{Na}$ Tabela 8 observa-se os dados da PI, da PE, da AI e da I para todo período analisado nas três fitofisionomias consideradas.

Tabela 8 - Totais das partições pluviométricas para as fitofisionomias (mm)

\begin{tabular}{ccccccccc|c}
\hline FITOFISIONOMIA & PI $(\mathrm{mm})$ & PI (\%) & PE $(\mathrm{mm})$ & PE (\%) & Al (mm) & Al (\%) & I (mm) & I (\%) \\
\hline CERRADO & $1.083,3$ & 75,7 & 339,3 & 23,7 & 736,2 & 51,5 & 376,9 & 26,4 \\
\hline CERRADÃO & $1.063,6$ & 74,4 & 331,5 & 23,2 & 735,2 & 51,4 & 384,9 & 26,9 \\
\hline MATA CILIAR & $1.113,9$ & 77,9 & 372,9 & 26,1 & 742,0 & 51,9 & 338,0 & 23,6 \\
\hline
\end{tabular}

PI - precipitação interna; PE - precipitação efetiva; AI - abstração inicial; I - Interceptação

A partir da observação da Tabela 8, verifica-se em valores absolutos e relativos que a maior PI ocorreu na fitofisionomia mata ciliar e a menor no cerradão. Em função da maior PI ter ocorrido na mata ciliar, encontramos também uma PE menor no cerradão. O maior índice de I foi encontrado na fitofisionomia cerradão, isto explicado pela menor PI, pois, as copas das árvores possuem um maior poder de retenção de água.

Os menores índices de AI foram encontrados na fitofisionomia mata ciliar, evidenciando uma maior contribuição desta com o abastecimento dos aquíferos. A AI que registrou para as áreas de cerrado na BHQXD foi de 51,58\%, sendo muito superior aos índices sugeridos pelo método do Curve Number $(\mathrm{CN})$, de $20 \%$.

No trabalho de Mello et al. (2003), é proposto a aplicação de modelo matemática para a determinação da AI em microbacias de escoamento efêmero, em função das variáveis que um determinado evento pluviométrico possa apresentar. Os resultados mostraram que para microbacias de escoamento efêmero os valores de AI podem ter uma alta variabilidade, e que, podem ser muito inferiores aos 20\% sugeridos pela USDA (United States Department of Agriculture). Ressalta-se que a utilização do método $\mathrm{CN}$ em território brasileiro deve ser adaptada.

Os dois períodos com maiores índices pluviométricos foram o outono e o verão (1240,3 mm). Considerando os dois períodos têm-se uma PI de 898,6 mm (72,5\%) e uma PE de $282 \mathrm{~mm}(22,7$ \%). A I atingiu um valor de 338,2 mm (27,3\%) contra 616,6 mm (49,7\%) de AI.

As análises dos dados dos outros períodos, inverno e primavera, têm-se uma P de $190 \mathrm{~mm}$ e uma PI de $160 \mathrm{~mm}(84,2 \%)$. A PE apresentou o valor de 41,7 $\mathrm{mm}(21,9 \%)$ e a AI foi de $121,1 \mathrm{~mm}$ $(63,8 \%)$. O volume de I apresentado para os dois períodos de menor P (inverno e primavera) foi de $24,9 \mathrm{~mm}(13,1 \%)$.

Observa-se que a AI no período de seca atingiu um percentual de 63,8 ao passo que no período chuvoso atingiu apenas 49,7\%. Quando da $\mathrm{P}$ em períodos de seca há uma tendência de maior I relativa e uma maior AI, devido, provavelmente, à menor umidade neste período, quando temos chuvas de baixo volume e intensidade. Em geral em períodos de estiagem, as chuvas possuem menores intensidades e as plantas, animais etc. absorvem parte da $\mathrm{P}$, talvez em maior percentual que em períodos chuvosos. Ao contrário nas estações chuvosas a I e a AI tendem a ser menores percentualmente, intensificando, por exemplo, o processo de escoamento superficial. 


\section{CONSIDERAÇÕES FINAIS}

Considerando-se o período analisado de novembro de 2009 a outubro de 2010, relativo a uma P de 1430,3 mm e a partir das observações, dos resultados e das discussões apresentadas, concluí-se que as partições pluviométricas tiveram o seguinte comportamento em relação às fitofisionomias analisadas e à sazonalidade:

As análises de variância, ao nível de $5 \%$ de probabilidade, mostraram que no período do verão e do outono não houve diferenças significativas entre as três fitofisionomias (cerrado, cerradão e mata ciliar) para as partições pluviométricas PI, PE, AI e I fato devido às plantas não apresentarem estresse hídrico neste período e os volumes pluviométricos serem considerados altos entre todos os períodos.

No período do inverno a PI foi maior no cerrado e no cerradão em relação à mata ciliar, provavelmente devido à menor I destas duas fitofisionomias, elevando os valores de PI; O menor volume de PI na fitofisionomia mata ciliar foi devido a sua maior área foliar do dossel, e, consequentemente, os maiores volumes de PI ocorreram na fitofisionomia cerrado.

No inverno, a I e a PE não foram diferentes estatisticamente em relação as três fitofisionomias. No entanto, a AI no inverno foi menor na fitofisionomia mata ciliar em relação ao cerrado, provavelmente, devido ao maior escoamento superficial no cerrado, uma vez que a AI é deduzida a partir da PE;

No período da primavera, a I no cerrado foi menor do que no cerradão e na mata ciliar, provavelmente, devido à menor área foliar do dossel;

As médias das partições pluviométricas das três fitofisionomias no período total considerado foram de: $76 \%$ para a PI, 25,6\% para a I, 24,3\% para a PE e de 51,6\% para a AI. No caso específico da AI, torna-se importante caracterizar, além do tipo e densidade de vegetação, o evento pluviométrico, ou seja, a intensidade de cada chuva, pois, o escoamento superficial é dependente desta condição e da capacidade de infiltração de água no solo.

\section{REFERÊNCIA BIBLIOGRÁFICA}

ARCOVA, F.C.S.; CICCO, V. de; ROCHA, P.A.B. Precipitação efetiva e interceptação das chuvas por floresta de Mata Atlântica em uma microbacia experimental em Cunha - São Paulo. Revista Árvore, Viçosa-MG, mar.-abr., v. 27, n.002, p.257-262, 2003. Disponível em: <http://redalyc.uaemex.mx/pdf/488/48827214. pdf $>$. Acesso em: 30 ago. 2010.

ASSUNÇÃO, H.F.; SCOPEL, I.; SANTOS, W.B. Caracterização espacial do clima no município de Jataí. In: CONGRESSO BRASILEIRO DE AGROMETEOROLOGIA, 11, 1999, Florianópolis. Anais..., Florianópolis: Sociedade Brasileira de Agrometeorologia, 1999. Editado em CD-ROM.

CONTI, J.B.; FURLAN, S.A. Geoecologia: O clima, os solos e a biota. In: Ross, J.L.S (Org.) Geografia do Brasil. São Paulo: Edusp, 2003.

DUNNE, T.; LEOPOLD, L.B. Water: in environmental planning. San Francisco: W.H. Freeman and Company, 1972.

FERREIRA, S.J.F; LUIZÃO, F.J.; DALLAROSA, R.L.G. Precipitação interna e interceptação da chuva em floresta de terra firme submetida à extração seletiva de madeira na Amazônia Central. Acta Amazonica, Manaus, vol.35 (1), p.55-62, 2005. Disponível em: <http://www.scielo.br/pdf/aa/v35n1/v35n1a08.pdf > Acesso em: 17 mai. 2011.

GÊNOVA, K.B. de; HONDA, E.A.; DURIGAN, G. Interceptação da chuva em diferentes modelos de plantio de restauração de mata ciliar em região de cerrado. Revista do Instituto Florestal - IF, São Paulo, n.31, p.281-285, jul. 2007. Disponível em: <http://www.iflorestal.sp.gov.br/publicacoes/serie_registros/ IFSerReg31/Karine.pdf $>$. Acesso em: 27 set. 2010.

LIMA, W. P. Precipitação. Notas de aula: Piracicaba-SP, 2000.

LIMA, W. P.; NICOLIELO, N. Precipitação efetiva e interceptação em florestas de pinheiros tropicais e em 
reserva de cerradão. Revista do Instituto de Pesquisas e Estudos Florestais (IPEF), Piracicaba-SP, n.24, p.43-46, ago. 1983. Disponível: http://www.ipef.br/publicacoes/scientia/nr24/cap04.pdf. Acesso: 31 out.2011. MELLO, C.R. de; LIMA, J.M. de; SILVA, A.M. da; LOPES, D. Abstração inicial da precipitação em microbacia hidrográfica com escoamento efêmero. Revista Brasileira de Engenharia Agrícola e Ambiental. Campina Grande-PB, DEAg/UFCG, V.7, n.3, p.494-500, 2003. Disponível em: <http://www.scielo.br/pdf/ rbeaa/v7n3/v7n3a15.pdf $>$. Acesso em: 26 abr. 2011.

OLIVEIRA, L.L. de; COSTA, R.F.; SOUSA, F.A.S.; COSTA, A.C.L,; BRAGA, A.P. Precipitação efetiva e interceptação em Caxiuanã, na Amazônia Oriental. Acta Amazonica, Manaus, v. 38, n.4, p.723-732, 2008.

ONOZAWA, Y.; CHIWA, M.; KOMATSU, H.; OTSUKI, K. Rainfall interception in a moso bamboo (Phyllostachys pubescens) forest. The Japanese Forest Society and Springer, 2009, 14: 111-116. Disponível em: $<$ http://www.springerlink.com/content/w42384781p93h115/>. Acesso em: 17 mai. 2011.

PROJETO RADAMBRASIL. Folha SE. 22 Goiânia: geologia, geomorfologia, pedologia, vegetação, uso potencial da terra / Projeto RADAMBRASIL. - (Levantamento de recursos naturais; v. 31) il., mapas. - Rio de Janeiro: O Projeto, 1983.

Trabalho enviado em janeiro de 2013

Trabalho aceito em fevereiro de 2013 